\title{
Burning Velocities of Marginally Flammable Refrigerant-Air Mixtures
}

John L. Pagliaro
Gregory T. Linteris

This publication is available free of charge from:

https://doi.org/10.6028/NIST.TN.1988 


\title{
Burning Velocities of Marginally Flammable Refrigerant-Air Mixtures
}

\author{
John L. Pagliaro \\ Gregory T. Linteris \\ Energy and Environment Division \\ Engineering Laboratory
}

This publication is available free of charge from:

https://doi.org/10.6028/NIST.TN.1988

May 2018

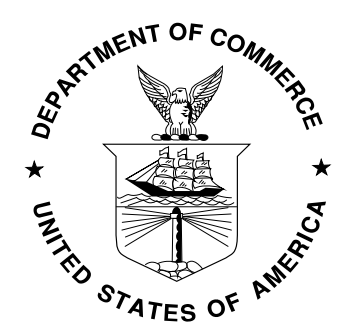

U.S. Department of Commerce Wilbur L. Ross, Jr., Secretary

National Institute of Standards and Technology Walter Copan, NIST Director and Undersecretary of Commerce for Standards and Technology 
Certain commercial entities, equipment, or materials may be identified in this document in order to describe an experimental procedure or concept adequately. Such identification is not intended to imply recommendation or endorsement by the National Institute of Standards and Technology, nor is it intended to imply that the entities, materials, or equipment are necessarily the best available for the purpose.

National Institute of Standards and Technology Technical Note 1988

Natl. Inst. Stand. Technol. Tech. Note 1988, 20 pages (May 2018)

CODEN: NTNOEF

This publication is available free of charge from:

https://doi.org/10.6028/NIST.TN.1988 


\title{
Burning Velocities of Marginally Flammable Refrigerant- Air Mixtures ${ }^{* \dagger}$
}

\author{
John L. Pagliaro and Gregory T. Linteris \\ National Institute of Standards and Technology, Gaithersburg, Maryland
}

\begin{abstract}
Refrigerant working fluids have been predicted to be large contributors to the increase in radiative forcing of the earth. Consequently, existing compounds will soon be phased out. Low-GWP replacements exist, but they tend to be mildly flammable, and there is a need to understand their flammability properties so that effective building codes and standards can be written to address their application. The burning velocities of interest are in the range of $1 \mathrm{~cm} / \mathrm{s}$ to $10 \mathrm{~cm} / \mathrm{s}$, and hence are challenging to measure. To understand the challenges and properties of the new agents, experimental measurements and numerical predictions have been made for representative refrigerant-air mixtures. Burning velocities were measured using a constant pressure spherical chamber with highspeed imaging of the shadowgraph image of the propagating spherical flame. The flame propagation rate as a function of flame radius was used to estimate the effects of stretch, and to determine the un-stretched laminar burning velocity. For comparison, the burning velocity was also predicted numerically using a detailed kinetic mechanism for hydrofluorocarbon combustion developed at the National Institute of Standards and Technology (NIST).
\end{abstract}

\section{Introduction/Background}

Vapor-compression systems are widely used for refrigeration and for space conditioning in buildings. As a result of the Montreal Protocol [1], many of the high ozone-depletion potential (ODP) working fluids, for example the chlorofluorocarbons (CFCs), have been largely phased out. Their replacements, the hydrofluorocarbons (HFCs), have zero ODP, but like their predecessors, also have a large global warming potential (GWP). The contribution of the HFCs to the total radiative forcing of the Earth is projected to be large, estimated to be about $20 \%$ of the total increase in radiative forcing between 2012 and 2050 [2]. Alternatives exist but have not been adopted largely because of the absence of building codes and standards for their safe use. Unfortunately, the properties that make these compounds break down in the troposphere, adding double bonds or hydrogen atoms, also makes them more flammable. Hence, flammability is an additional parameter that the Heating, Ventilation, Air-Conditioning, and Refrigeration (HVAC\&R) industry must consider when optimizing the performance of working fluids (beyond the presently considered thermodynamic, fluid dynamic, heat transfer and toxicological properties). The adopted working fluids will likely involve blends of individual

\footnotetext{
* Official contribution of NIST, not subject to copyright in the United States. Certain commercial equipment, instruments, and materials are identified in this paper to adequately specify procedure. Such identification does not imply recommendation or endorsement by the National Institute of Standards and Technology.

${ }^{\dagger}$ Also appeared in the Proceedings of the 2016 Spring Technical Meeting, Eastern States Section of the Combustion Institute, Princeton University, March 13-16, 2016
} 
compounds. To facilitate their safe use, it is essential for industry to have data on their combustion properties as well as a test metric to rank their flammability and predict their fullscale behavior.

As a first step in providing the required information, the present work examines two representative compounds: the pure agent R-32 $\left(\mathrm{CH}_{2} \mathrm{~F}_{2}\right)$ and its combination with $\mathrm{R} 125\left(\mathrm{C}_{2} \mathrm{HF}_{5}\right)$. Equal mass fractions of these two compounds comprise the refrigerant R410A, which is ubiquitous in residential air conditioners and heat pumps in the US, while the refrigerant R-32 is being used in Japan. The behavior of these two refrigerants is compared to that of the new lowGWP hydrofluoro-olefin (HFO) compound R-1234yf $\left(\mathrm{CH}_{2} \mathrm{CFCF}_{3}\right)$, which has been of great interest recently as a substitute compound. The flammability of these compounds is discussed with regard to burning velocity, which is the subject of developing international codes and standards [3, 4], is a measure of the overall reactivity of the agent, and is used to simulate fullscale explosions $[5,6]$. The present work experimentally measures and numerically predicts the un-stretched laminar burning velocity of $\mathrm{CH}_{2} \mathrm{~F}_{2} / \mathrm{C}_{2} \mathrm{HF}_{5}$ mixtures with air, and determines the influence of stretch on burning velocity and ignitability.

\section{Experiment and Data Reduction}

The experimental and data reduction techniques used in this work are outlined below, with more details available in ref. [7]. The visually accessible $30 \mathrm{~L}$ spherical chamber and z-type shadowgraph system for high-speed video recording are based on the design of Faeth and coworkers [8-11] and Takizawa et al. [12]. Mixtures are prepared in the chamber via the partial pressure method, circulated for 3 minutes (using a metal bellows pump) to ensure complete mixing, then given 10 minutes to settle. The sample reactants are $\mathrm{CH}_{4}$ (Matheson Tri-Gas, 99.97\% purity), $\mathrm{C}_{3} \mathrm{H}_{8}$ (Scott Specialty Gases, $99.0 \%$ purity), $\mathrm{C}_{2} \mathrm{HF}_{5}$ (Allied Signal Chemicals, $99.5 \%$ purity), $\mathrm{CH}_{2} \mathrm{~F}_{2}$ (Honeywell, Genetron 32, $99.9 \%$ purity), house de-ionized water, and house air that is filtered and dried. To initiate combustion, a capacitive discharge system generates a spark (with an estimated energy of $0.05 \mathrm{~mJ}$ to $500 \mathrm{~mJ}$ ) at the center of the chamber. For each test, the ignition energy is gradually increased until ignition occurs, ensuring that the supplied energy is within an order of magnitude of the minimum ignition energy (MIE).

A high-speed camera and shadowgraph system provide images of the spherical flame propagation. Custom-developed image analysis software tracks the flame position (at the top, bottom, left, and right edges) as a function of time in the videos. For slow flames, buoyancy affects the burned gas velocity and the local stretch rate; the influence of buoyancy is minimized by using the flame propagation data only from the two horizontal directions [12-14]. The temporal evolution of the flame radius $R_{f}$ yields the stretched flame speed, which is further processed to determine the burning velocity as a function of the stretch rate, as well as the unstretched value (from extrapolation).

To capture the relationship between burning velocity and stretch rate, the range of flame radii included in the data reduction is limited, as recommended in the literature [14-19]. For example, the change in burning velocity with flame radius can be affected by such factors as confinement, radiation, ignition, and flame instabilities, depending on the size of the expanding sphere. Consequently, the upper bound $R_{f U}$ is fixed at $3.5 \mathrm{~cm}$ for all tests to minimize confinement and 
radiation effects, and insure that all flame images were free of any cellularity. The lower bound of flame radii $\left(R_{f L}\right)$ is also limited, to exclude data potentially influenced by the ignition event or extreme nonlinearity during the early stages of flame propagation. This latter effect (which is not always captured by current extrapolation methods) depends on the mixture Lewis number, and can lead to considerable errors in un-stretched results $[16,19]$. Thus, the lower bound on included data $R_{f L}$ ranges between $0.5 \mathrm{~cm}$ and $2.0 \mathrm{~cm}$. The value is determined manually for each mixture by estimating (from a plot of $R_{f}$ vs time) the value of $R_{f}$ above which the curve is nearly linear. In a select number of cases, $R_{f L}$ was set to $1.5 \mathrm{~cm}(\phi=0.90$ and $\phi=1.08)$ or $2.0 \mathrm{~cm}$ $(\phi=0.96)$ so that the effects of extreme initial nonlinearity and ignition were both minimized.

For spherically symmetrical flame propagation, the flame speed in the laboratory reference frame corresponds to the burned gas velocity $S_{b}=d R_{f} / d t$, and is a function of the stretch rate, defined as $K=\left(2 / R_{f}\right)\left(d R_{f} / d t\right)$, where $K$ is the stretch rate $\left(\mathrm{s}^{-1}\right), A_{f}$ is the flame surface area, and $t$ is time [20]. As seen in the equation, the stretch rate decreases as the flame radius increases. Extrapolation to zero-stretch conditions is done using the relationship derived by Ronney and Sivashinsky [21] (for highly stretched flames with large Le), and later expressed in the following form by Kelley et al. [22],

$$
S_{b}^{0} t+c_{1}=R_{f}+2 L_{b} \ln R_{f}-4 \frac{L_{b}^{2}}{R_{f}^{2}}-\frac{8}{3} \frac{L_{b}^{3}}{R_{f}^{3}}
$$

in which the variable $c_{1}$ is an integration constant. The variables $S_{b}{ }^{0}, L_{b}$, and $c_{1}$ are determined using a non-linear least squares optimization routine that fits the above equation to the experimentally measured flame radius versus time $R_{f}(t)$. From conservation of mass across the flame sheet, the un-stretched unburned gas velocity is then obtained from $S_{u}{ }^{0}=\left(\rho_{b} / \rho_{u}\right) S_{b}{ }^{0}$, where $S_{u}{ }^{0}$ is the unburned gas velocity, and $\rho_{u}$ and $\rho_{b}$ the unburned and burned gas densities. The burned gas is assumed to be in chemical equilibrium and $\rho_{b}$ is calculated using the Sandia EQUIL routine [23]. Tests are performed at $296 \pm 2 \mathrm{~K}$ and $101.33 \mathrm{kPa}$ for each mixture. For each test, the extrapolation equations are fit to the $R_{f}$ vs. $t$ data from the left and right side flame tracking locations. The fitting parameters $\left(S_{b}{ }^{0}, L_{b}\right.$, and $\left.c\right)$ from the two sides are then averaged to produce the reported burning velocities and burned gas Markstein lengths.

The experimental system and data reduction methods were validated in previous work [7]. Fig. 1 (from ref. [7]) shows the un-stretched burning velocity $S_{u}{ }^{0}$ using the present techniques for $\mathrm{CH}_{4}$ and $\mathrm{C}_{3} \mathrm{H}_{8}$-air flames, over a range of fuel-air equivalence ratios, together with data from outwardly propagating flames (OPFs) [18, 24-26] and counterflow flames [27, 28]. Numerical predictions using the Wang mechanism [29] are shown by the dashed line. An (L) or (NL) next to the reference in the figure legend specifies whether the dataset was extrapolated using linear or non-linear methods. For both $\mathrm{CH}_{4}$-air and $\mathrm{C}_{3} \mathrm{H}_{8}$-air flames, the burning velocities using the present methods are in excellent agreement with the previous results and with the numerical predictions.

The estimated uncertainties in the experimental determination of the burning velocity have been described in detail in ref. [7] for the same experimental apparatus (for hydrocarbon-air flames highly-inhibited by halogenated hydrocarbons). Uncertainties are reported as expanded uncertainties $U=k u_{c}$ determined from a combined standard uncertainty $u_{c}$ and a coverage factor 
$k=2$ corresponding to a level of confidence of $95 \%$. Based on those analyses, the maximum expanded relative uncertainty in $S_{u}{ }^{0}$ is $13 \%$. However, measurement uncertainty is not the only cause of inaccuracy in the reported data. Buoyancy, radiation, and non-linear stretch effects can cause the inferred value of $S_{u}{ }^{0}$ to differ from that of an ideal experiment, and this may vary with reactants. While these factors cannot be eliminated in the present study, their influence was minimized by using only the portion of the $R_{f}$ vs. $t$ data described above.

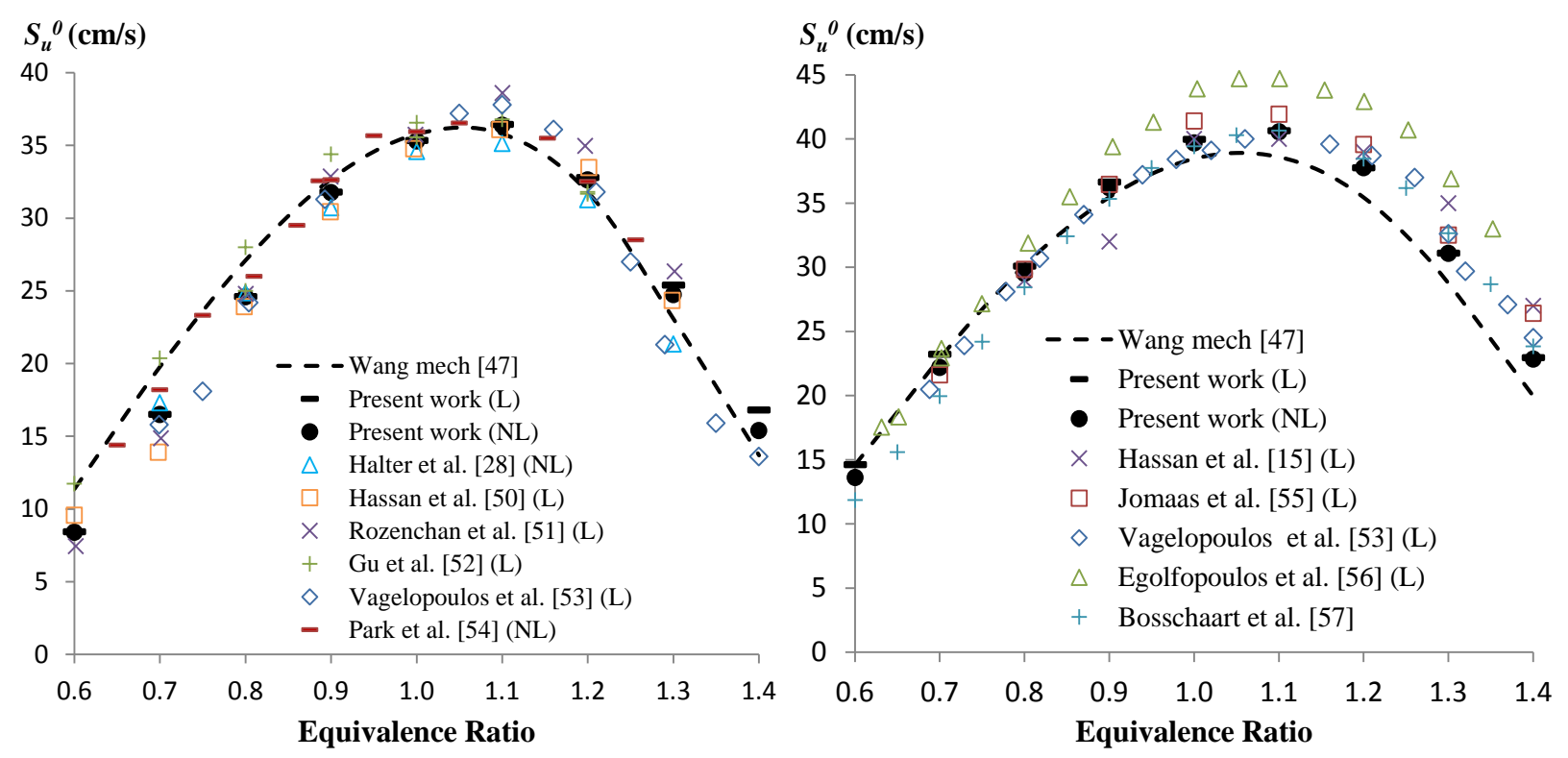

Fig. 1: Burning velocity of premixed $\mathrm{CH}_{4}$-air (left) and $\mathrm{C}_{3} \mathrm{H}_{8}$-air (right) flames as a function of equivalence ratio, together with previously published results (symbols) and 1-D planar adiabatic simulation (dashed line). Figures (and references therein) from ref. [7].

\section{Numerical Modeling}

For the refrigerant-air flames, the flame structures and burning velocities are predicted with the Sandia PREMIX flame code and associated kinetics and transport processors [30-32], for reactants at an initial temperature and pressure of $298.15 \mathrm{~K}$ and $101.33 \mathrm{kPa}$. The Soret effect, and mixture-averaged molecular diffusion are included, and GRAD and CURV values are set to 0.05 to yield 310 to 420 active grid points. The comprehensive reaction mechanism (52 species and 621 reactions) is adopted from the NIST HFC mechanism [33, 34], with updates as described in refs. [7, 35]. The mechanism has been partially validated in earlier work, and more recently via burning velocity measurements and predictions for $\mathrm{CH}_{4}$-air flames inhibited by $\mathrm{C}_{2} \mathrm{HF}_{5}[36]$. 


\section{Results and Discussion}

\section{Calculated Flame Temperatures and Burning Velocities for $\mathrm{CH}_{2} \mathrm{~F}_{2} / \mathrm{C}_{2} \mathrm{HF}_{5}$ Mixtures}

The calculated adiabatic flame temperature $T_{a d}$ (constant pressure, enthalpy) as a function of equivalence ratio for the $\mathrm{CH}_{2} \mathrm{~F}_{2} / \mathrm{C}_{2} \mathrm{HF}_{5}$ mixtures in air is shown in Fig. 2. The equivalence ratio is based on the stoichiometeric reaction of the fuel mix to the most stable equilibrium products (typically $\mathrm{HF}, \mathrm{CO}_{2}, \mathrm{COF}_{2}$, and $\mathrm{H}_{2} \mathrm{O}$, depending upon the fuel mix and $\phi$ ). For $\mathrm{CH}_{2} \mathrm{~F}_{2}$, the peak value $\left(T_{a d, m a x}\right)$ is $2213 \mathrm{~K}$, nearly the same as for methane-air flames $(2230 \mathrm{~K})$, while for pure $\mathrm{C}_{2} \mathrm{HF}_{5}$-air flames, $T_{a d, \max }=1805 \mathrm{~K}$. Fig. 3 shows $T_{a d, \max }$ and the value of $\phi$ at which the peak occurs, $\phi\left(T_{a d, \text { max }}\right)$, as a function of the mass fraction of $\mathrm{C}_{2} \mathrm{HF}_{5}$ in the fuel $Y_{\mathrm{C}_{2} \mathrm{HF}_{5}}$. As illustrated, $T_{a d \text { max }}$ decreases roughly linearly with increasing $\mathrm{C}_{2} \mathrm{HF}_{5}$ mass fraction, while $\phi\left(T_{a d, \max }\right)$, is constant at $\phi=1.03$. For the refrigerant R-410A mixtures $\left(Y_{C_{2} \mathrm{HF}_{5}}=0.5\right)$ in air, $T_{a d, \max }=1972 \mathrm{~K}$.

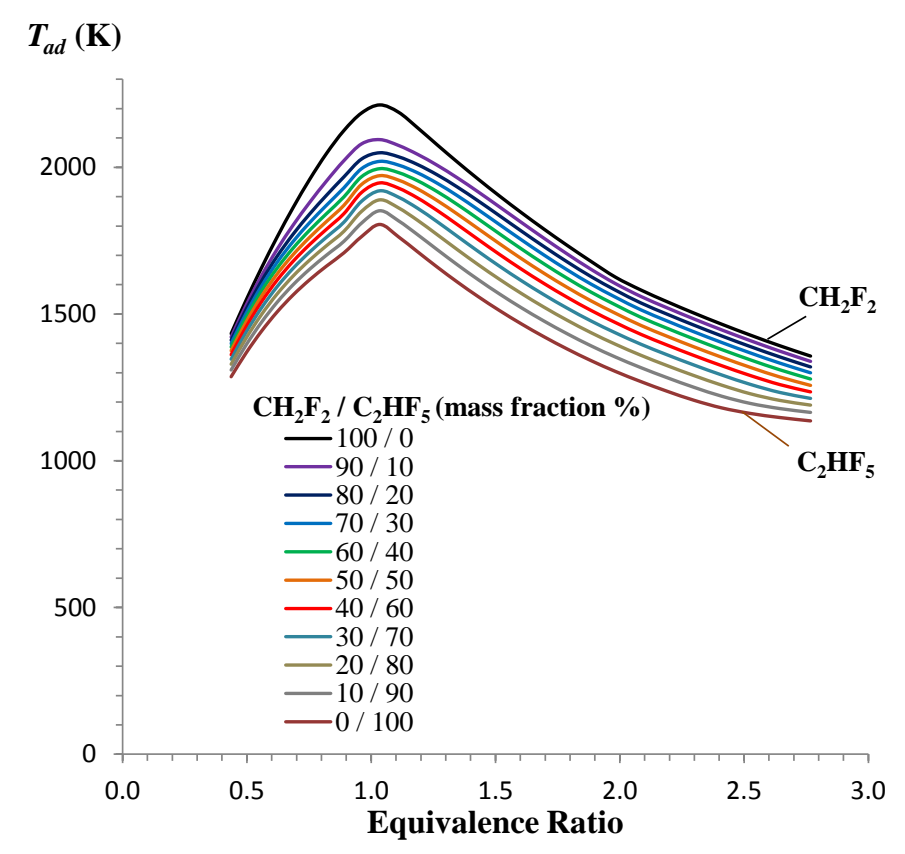

Fig. 2: Calculated adiabatic flame temperature for $\mathrm{CH}_{2} \mathrm{~F}_{2} / \mathrm{C}_{2} \mathrm{HF}_{5}$ blends as a function of equivalence ratio.

The calculated un-stretched, planar, laminar, 1-D burning velocity $S_{u}{ }^{0}$ as a function of the fuel-air equivalence ratio for $\mathrm{CH}_{2} \mathrm{~F}_{2} / \mathrm{C}_{2} \mathrm{HF}_{5}$ mixtures is shown in Fig. 4 for dry (solid lines) and $100 \%$ relative humidity air (dashed lines). As indicated, increasing the $\mathrm{C}_{2} \mathrm{HF}_{5}$ mass fraction from $0 \%$ to $100 \%$ decreases the peak burning velocity $S_{u}{ }^{0}$, max from $5.95 \mathrm{~cm} / \mathrm{s}$ to $0.56 \mathrm{~cm} / \mathrm{s}$, and changes the value of $\phi$ for $S_{u}{ }^{0}$, $\max \left(\phi\left(S_{u}{ }^{0}, \max \right)\right)$ towards leaner mixtures. As $Y_{C_{2} H F_{5}}$ increases above $60 \%$, however, the value of $\phi\left(S_{u}{ }^{0}\right.$,max $)$ abruptly shifts to a richer condition, $\phi=1.2$. This is illustrated more clearly in Fig. 5, which shows the peak burning velocity $S_{u}{ }^{0}, \max$ and $\phi\left(S_{u}{ }^{0}, \max \right)$ as a function of the mass fraction of $\mathrm{C}_{2} \mathrm{HF}_{5}$ in the fuel. The peak burning velocity decreases smoothly until $Y_{\mathrm{C}_{2} \mathrm{HF}_{5}} \approx 0.70$, and then less rapidly as $Y_{\mathrm{C}_{2} \mathrm{HF}_{5}}$ increases further. While the $\phi\left(T_{a d, \max }\right)$ (from Fig. 3) is constant at 1.03 (for all mixtures), $\phi\left(S_{u}{ }^{0}\right.$ max $)$ (Fig. 5) is much lower for pure $\mathrm{CH}_{2} \mathrm{~F}_{2}$-air mixtures at which $\phi\left(S_{u}{ }^{0}\right.$,max $)=0.96$, and becomes progressively leaner with added $\mathrm{C}_{2} \mathrm{HF}_{5}$, up to $Y_{C_{2} \mathrm{HF}_{5}}=0.6$ at which $\phi\left(S_{u}{ }^{0}, \max \right)=0.62$. For a slight increase in $Y_{C_{2} \mathrm{HF}_{5}}$ to $0.7, \phi\left(S_{u}{ }^{0}\right.$,max $)$ increases 
abruptly to 1.2 and remains at the value for $Y_{\mathrm{C}_{2} \mathrm{HF}_{5}}=0.8,0.9$, or 1.0. This behavior implies that at $Y_{C_{2} H_{5}} \approx 0.65$, the kinetic pathways for reaction of the fuel mix changes significantly as compared to those that at lower $\mathrm{C}_{2} \mathrm{HF}_{5}$ loadings.

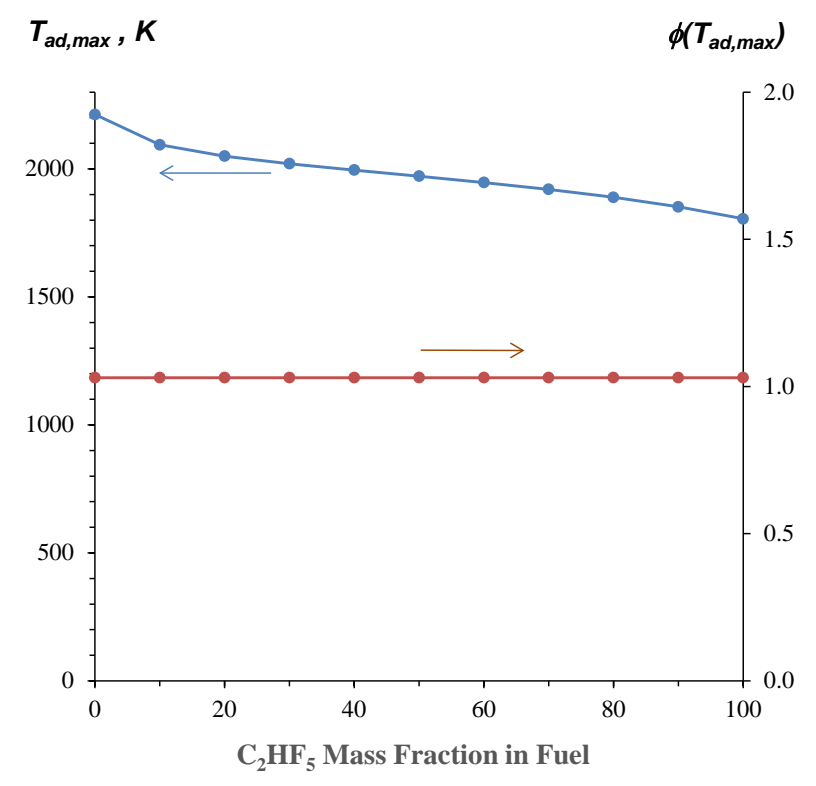

Fig. 3: Peak value of $T_{a d}$ and the value of $\phi$ at the peak $T_{a d}$ as a function of $\mathrm{C}_{2} \mathrm{HF}_{5}$ mass fraction in the fuel.

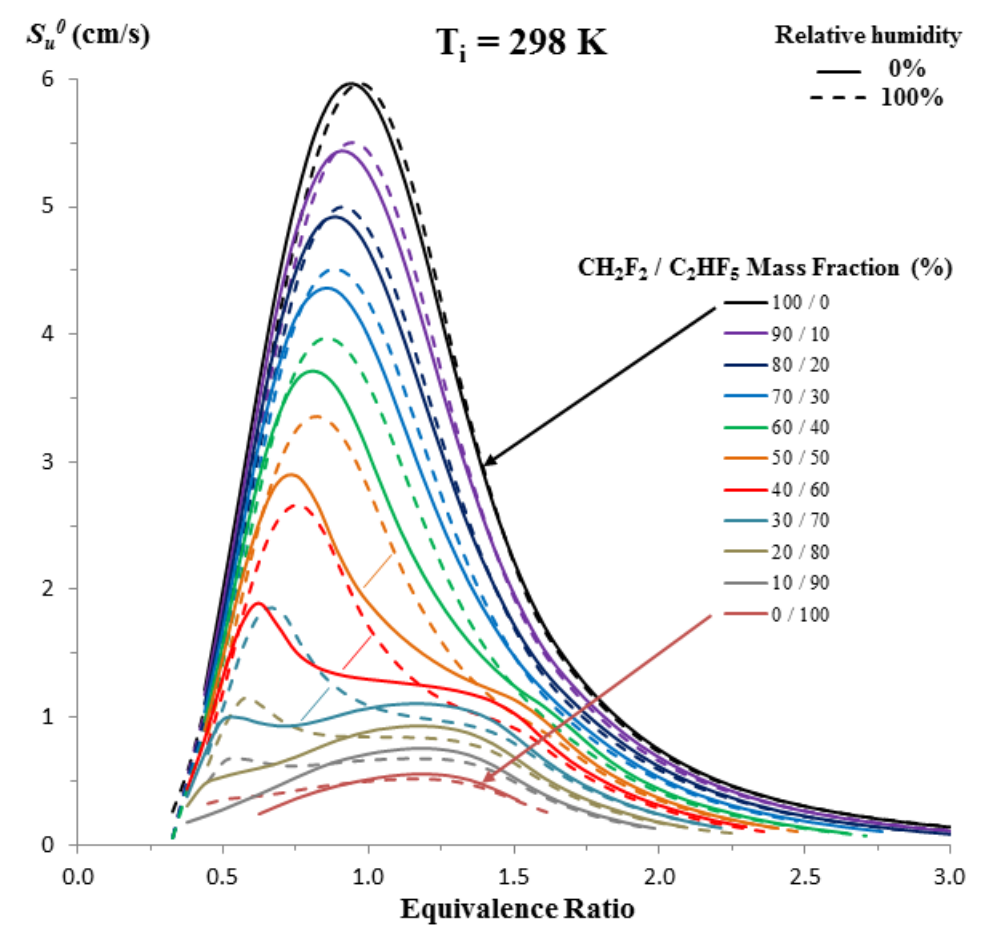

Fig. 4: Calculated burning velocity for $\mathrm{CH}_{2} \mathrm{~F}_{2} / \mathrm{C}_{2} \mathrm{HF}_{5}$ blends as a function of equivalence ratio and humidity. 


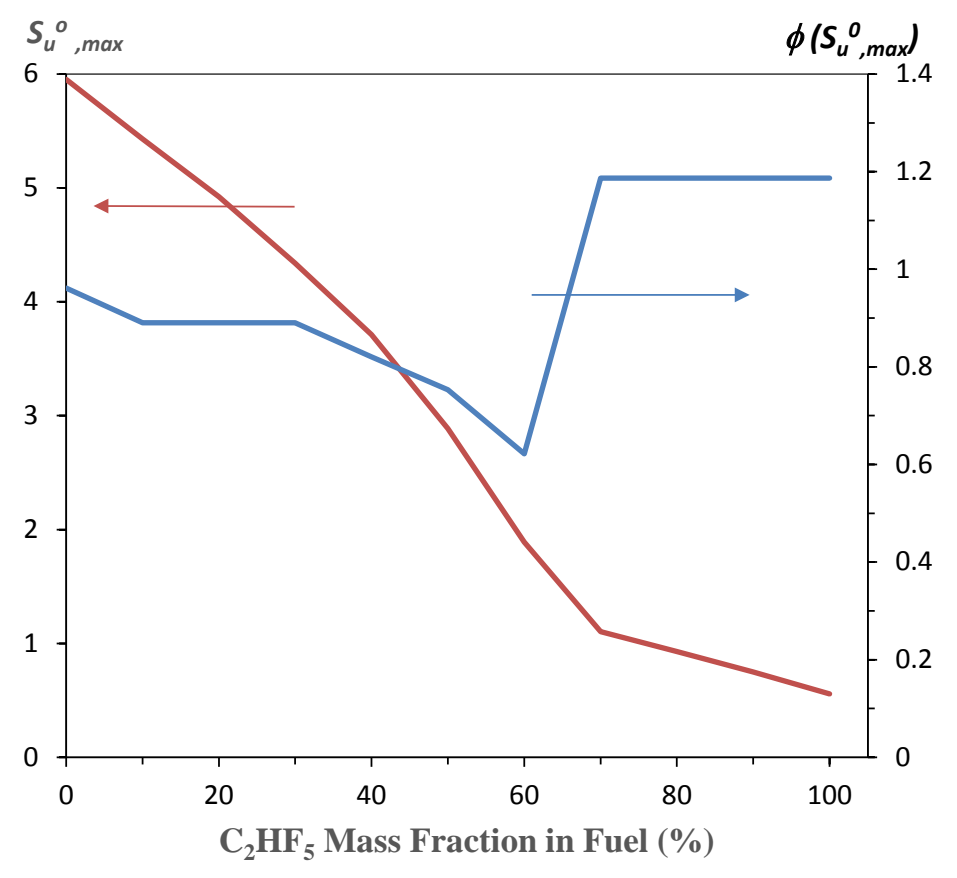

Fig. 5: Peak values of $S_{u}{ }^{0}$ and the value of $\phi$ at the peak $S_{u}{ }^{0}$, as a function of $\mathrm{C}_{2} \mathrm{HF}_{5}$ mass fraction in the fuel.

The effect of humidity on the $\mathrm{CH}_{2} \mathrm{~F}_{2} / \mathrm{C}_{2} \mathrm{HF}_{5}$ flames is also indicated in Fig. 4. For pure $\mathrm{CH}_{2} \mathrm{~F}_{2}-$ air flames, the effect of humidty is small, with $S_{u}{ }^{0}$ increased slightly for rich flames, and decreased slightly for lean flames. With increasing amounts of $\mathrm{C}_{2} \mathrm{HF}_{5}$, however, the influence of water vapor is substantial. For example with $\mathrm{CH}_{2} \mathrm{~F}_{2} / \mathrm{C}_{2} \mathrm{HF}_{5}$ mass fraction of $30 \% / 70 \%$, the calculated peak value of $S_{u}{ }^{0}$ is increased from $1.10 \mathrm{~cm} / \mathrm{s}$ to $1.83 \mathrm{~cm} / \mathrm{s}$.

The magnitudes of the burning velocities in Fig. 4 are of interest in the context of flammability limits and explosion propensity. The 50/50 mix of $\mathrm{CH}_{2} \mathrm{~F}_{2} / \mathrm{C}_{2} \mathrm{HF}_{5}(\mathrm{R} 410 \mathrm{~A}$ ) has a calculated $S_{u}{ }^{0}$,max of $2.9 \mathrm{~cm} / \mathrm{s}$ and is non-flammable as determined with ASTM-E-681. Nonetheless, the refrigerant R-1234yf $\left(\mathrm{CH}_{2} \mathrm{CFCF}_{3}\right)$ in dry air has a measured $S_{u}{ }^{0}$, max $=1.2 \mathrm{~cm} / \mathrm{s}$ and flammability limits of $6.8 \%$ and $12 \%$ [37]. That is, $\mathrm{CH}_{2} \mathrm{CFCF}_{3}$ has a peak burning velocity about $1 / 3$ that of R410A, yet is flammable, while R410A is not. Since the Lewis number affects both flame stability [38-40] and critical radius for sustained propagation [41, 42], it is of interest to examine the response of these flames to stretch.

In order to gain confidence in the model predictions for the mixtures of $\mathrm{CH}_{2} \mathrm{~F}_{2}$ and $\mathrm{C}_{2} \mathrm{HF}_{5}$, the calculated values of $S_{u}{ }^{0}$ are first compared with experimental measurements in the following section.

\section{Experimental Burning Velocities for $\mathrm{CH}_{2} \mathrm{~F}_{2}$-air and $\mathrm{CH}_{2} \mathrm{~F}_{2} / \mathrm{C}_{2} \mathrm{HF}_{5}$-air Mixtures}

The measured burning velocity of pure $\mathrm{CH}_{2} \mathrm{~F}_{2}$ in dry air is shown in Fig. 6 together with other measurements from the literature [43-48] (which are not stretch corrected). For this refrigerant, 
the present measurements are somewhat higher than the others for $0.96 \leq \phi \leq 1.2$, and $S_{u}{ }^{0}$ peaks at slightly leaner conditions $\left(S_{u}{ }^{0}=7.5 \mathrm{~cm} / \mathrm{s}\right.$ at $\left.\phi \approx 0.96\right)$ as compared to the other measurements $\left(S_{u}{ }^{0}=\right.$ to $6.1 \mathrm{~cm} / \mathrm{s}$ to $6.7 \mathrm{~cm} / \mathrm{s}$, at $\phi \approx 1.03$ to 1.2 ). The numerical predictions (for a 1-D, steady, planar flame; dashed line in Fig. 6) yield a peak burning velocity of about $6 \mathrm{~cm} / \mathrm{s}$ at $\phi=0.95$, which is somewhat lower, and at a leaner $\phi$, than most of the measurements.

For the mixtures of air with $90 \% / 10 \% \mathrm{CH}_{2} \mathrm{~F}_{2} / \mathrm{C}_{2} \mathrm{HF}_{5}$, the experimental measurements and numerically predicted burning velocities (Fig. 7) are in good agreement. Experiments were also attempted for leaner conditions for this mixture, as well as for other mixtures with increasing fractions of $\mathrm{C}_{2} \mathrm{HF}_{5}$; however, while ignition occurred for some conditions, sustained flame propagation could not be attained. For some conditions, the flames were initially ignited but then extinguished as the radius increased (a well-known effect in hydrocarbon-air flames due to the existence of a critical radius for sustained propagation). The unusually large critical radius for the lean flames, as well as the discrepancies in the experimental measurements in Fig. 6 may be due to Lewis number effects. Hence, the flame response to stretch for the present flames is examined.

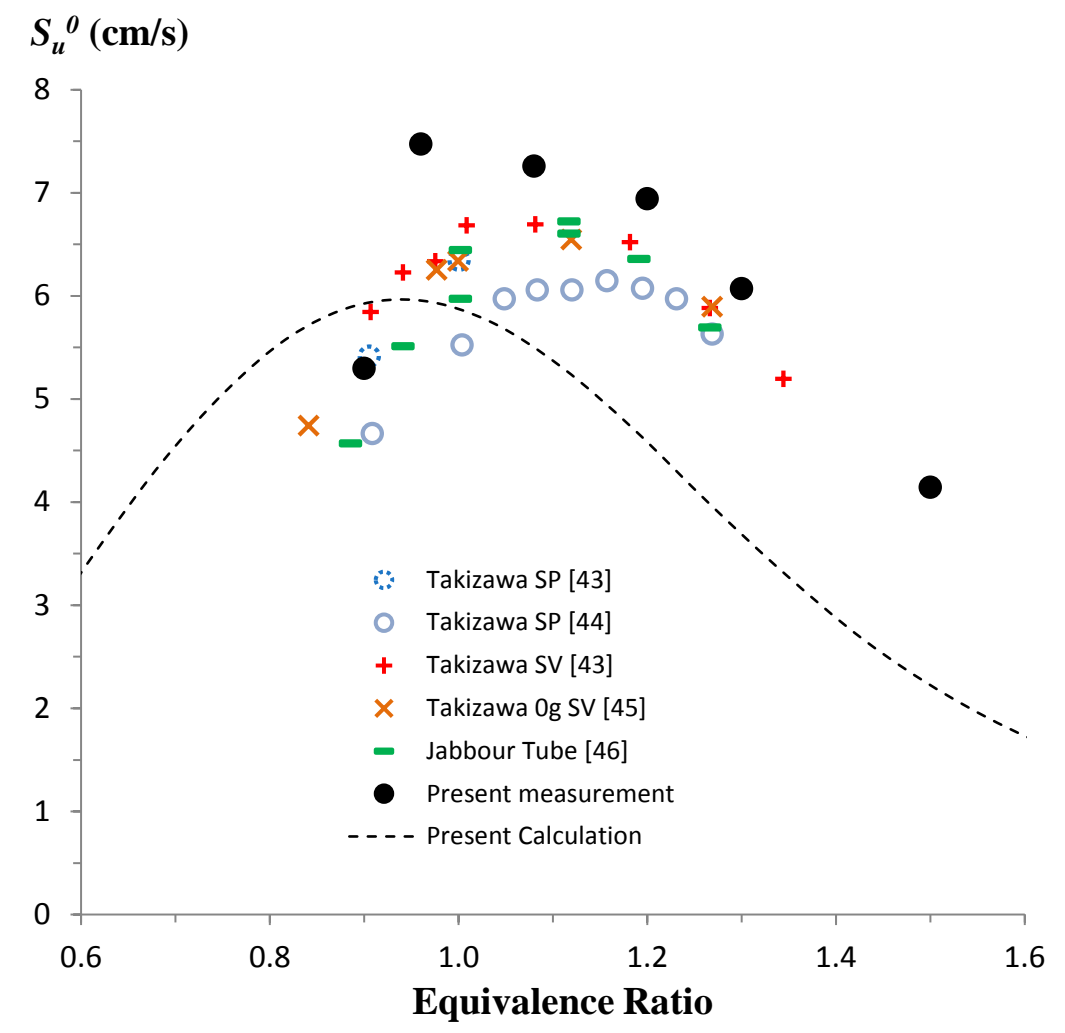

Fig. 6: Experimentally measured (points) and numerically predicted (lines) burning velocity of $\mathrm{CH}_{2} \mathrm{~F}_{2}$-air flames $\left(P_{\text {init }}=101.33 \mathrm{kPa}, T_{\text {init }}=298 \mathrm{~K}\right)$ as a function of equivalence ratio (SP: schlieren photography, SV: spherical vessel). 


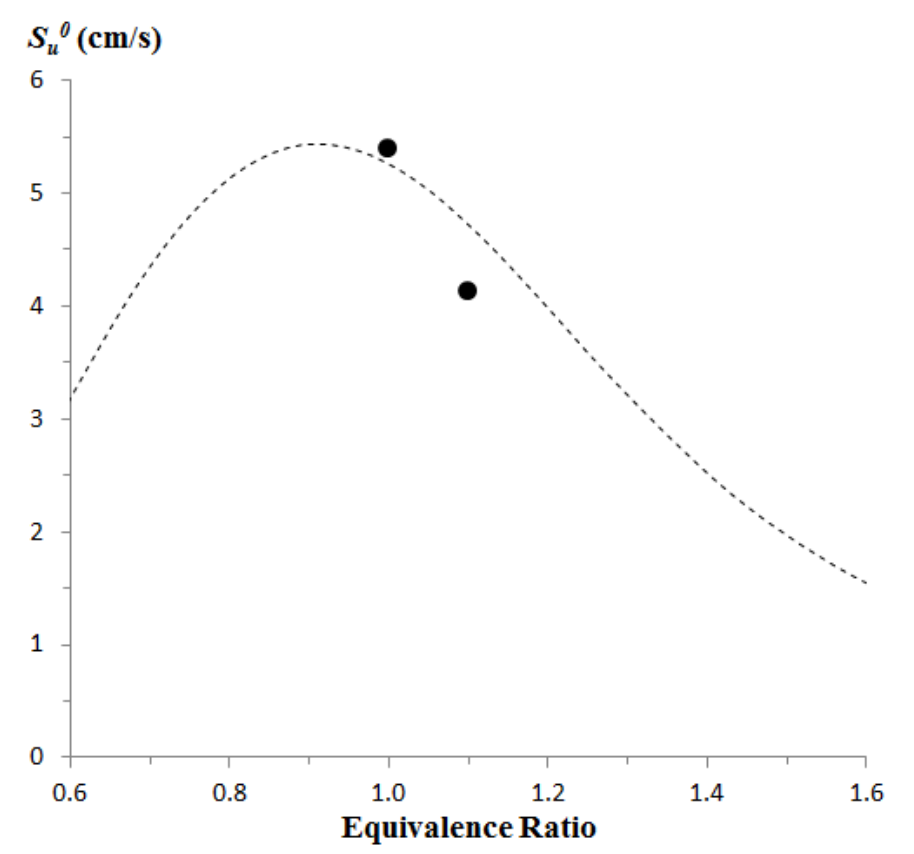

Fig. 7: Experimentally measured (points) and numerically predicted (lines) burning velocity of $\mathrm{CH}_{2} \mathrm{~F}_{2} / \mathrm{C}_{2} \mathrm{HF}_{5}$ - air flames $\left(Y_{C 2 H F 5}=0.10, P_{\text {init }}=101.33 \mathrm{kPa}, T_{\text {init }}=298 \mathrm{~K}\right)$ as a function of equivalence ratio.

\section{Stretch Effects on Experimental Burning Velocities for $\mathrm{CH}_{2} \mathrm{~F}_{2}$-air Mixtures}

As described above, in the present work, the un-stretched burning velocity $S_{u}{ }^{0}$ is determined via a non-linear extrapolation of the stretched burning velocities obtained as a function of flame radius. The burned gas velocity $S_{b}\left(d R_{f} / d t\right)$ vs. flame radius for the $\mathrm{CH}_{2} \mathrm{~F}_{2}$-air flames is shown in Fig. 8. All flames show an increase in $S_{b}$ with increasing flame radius; the effect is very mild for the richest flames $(\phi=1.5)$, but increases as $\phi$ decreases, and is very strong for $\phi=0.90$, for which $S_{b}$ approximately doubles as $R_{f}$ increases from $1.4 \mathrm{~cm}$ to $3.5 \mathrm{~cm}$. $S_{b}$ is plotted as a function of stretch rate in Fig. 9. As illustrated, the un-stretched burned gas velocities $S_{b}{ }^{0}\left(S_{b}\right.$ at $\mathrm{K}=0 \mathrm{~s}^{-1}$ ) are higher than $S_{b}$ at the largest radius, by up to $26 \%$. Moreover, the non-linear extrapolation may not be the best representation of the behavior at low stretch rates. For example, for the values of $\phi$ showing the most discrepancy between the present data and other data, different extrapolations to the zero stretch condition would produce better agreement with previous data. More research is needed to understand the proper treatment of the data for these fuels. 


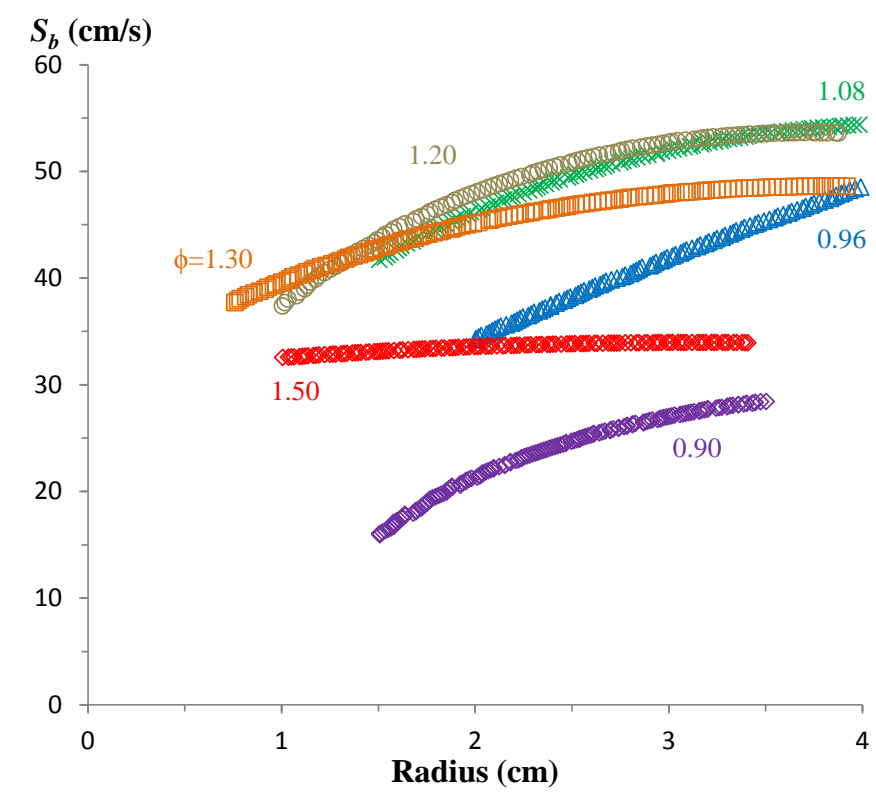

Fig. 8: Burned gas velocity $S_{b}$ versus flame radius for $\mathrm{CH}_{2} \mathrm{~F}_{2}$ in air at various equivalence ratios.

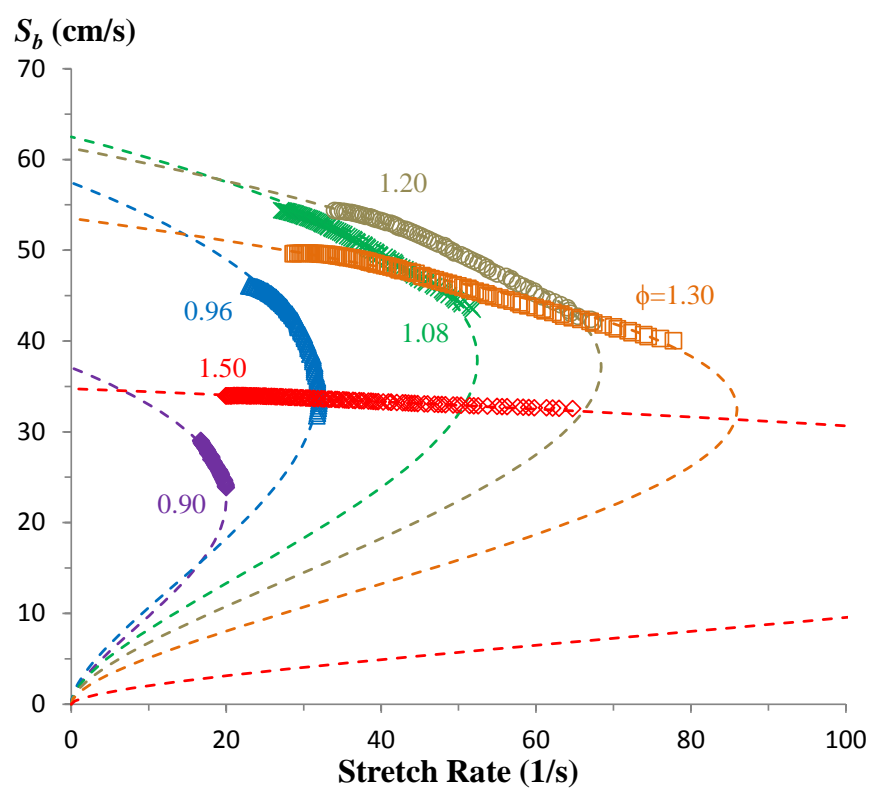

Fig. 9: Burned gas velocity $S_{b}$ versus stretch rate for $\mathrm{CH}_{2} \mathrm{~F}_{2}$ in air at various equivalence ratios (symbols are the experimental data and dashed lines are the non-linear fit).

Differences between the present data and previous measurements in different experiments may be due to the influence of stretch, or other factors. For example, the direct imaging experiments of outwardly propagating flames in refs. [43, 44] do not extrapolate to un-stretched conditions, and are subject to pressure rise in the chamber for flames at larger radii (chamber volume of 3.7 L). Other tests use a constant volume combustion bomb, either in normal gravity [43] or microgravity [45], and determine the burning velocity from measured pressure rise data. In each 
experimental run, data are obtained over a range of pressure and temperature of the unburned gases as the end gases are compressed by the advancing spherical flame. A curve is fit to the data of $S_{u}$ vs. unburned gas temperature and pressure, and used to extrapolate back to reference conditions $\left(P_{\text {init }}=101.33 \mathrm{kPa}, T_{\text {init }}=298 \mathrm{~K}\right)$. As the radius increases, however, $S_{b}$ is affected by both the changes in pressure and temperature, as well as differing stretch rates. Hence, it is not clear that the curve-fitting/extrapolation method is valid for these flames that are very sensitive to the stretch rate. Further, the hotter, higher pressure flames at larger radii may have greater radiative heat losses than typical hydrocarbon-air flames, since the product gases have an $\mathrm{HF}$ volume fraction of about 0.30 , and $\mathrm{HF}$ is a strong radiator in the IR. The vertical tube experiment [46-48], while it gives values similar to the other experiments (if the correct tube size is selected), is likely affected by flow in the unburned gases due to buoyancy and wall effects $[44,49]$. The relative importance of these effects for the different experimental methods is unknown, and would be worthy of investigation in the future.

As shown in Fig. 6, the numerically predicted un-stretched burning velocities (steady, 1-D, planar) for $\mathrm{CH}_{2} \mathrm{~F}_{2}$ - air disagree somewhat with the various experimental values (unsteady, 2-D or 3-D, spherical or cylindrical). This agreement is reasonable, however, considering the differences between the model and the experiments. The most important of these are likely the extrapolation to zero stretch rate, radiation heat losses, and the presence of buoyancy-induced flow, all of which are not included in the model. For example, near the edges of the horizontally propagating flames, buoyancy-induced flow in the burned and unburned gases may be modifying the stretch rate as compared to that estimated for a spherically propagating flame.

The Markstein lengths $L_{b}$ of the present refrigerant-air flames can be determined from the curves in Fig. 9, and Fig. 10 and Fig. 11 show $L_{b}$ as a function of $\phi$ for the pure $\mathrm{CH}_{2} \mathrm{~F}_{2}$-air, and $90 \%$ $\mathrm{CH}_{2} \mathrm{~F}_{2} / 10 \% \mathrm{C}_{2} \mathrm{HF}_{5}$ - air flames, respectively. For the range of $\phi$ indicated on the figures, $L_{b}>0$, and $L_{b}$ increases at leaner conditions. These values of $L_{b}$ are quite large: $L_{b}$ for $\mathrm{CH}_{2} \mathrm{~F}_{2}$ is about a factor of two larger than for propane at $\phi=0.6$, and hydrogen-air flames at $\phi=7$.

The Markstein lengths for $\mathrm{CH}_{2} \mathrm{CFCF}_{3}$-air mixtures has been estimated by Takizawa et al. [37]. For those mixtures, $L_{b} \approx-0.25$; i.e., is negative (i.e., the opposite of $\mathrm{CH}_{2} \mathrm{~F}_{2}$-air flames) and is much smaller in magnitude, increasing slightly in magnitude for leaner flames. Moreover, $L_{b}$ is also a function of the overall activation energy. As described by Takizawa at al. [37], the overall activation energy $E_{a}$ of $\mathrm{CH}_{2} \mathrm{~F}_{2}$-air flames is higher than that of $\mathrm{CH}_{4}$-air flames, and $E_{a}$ for $\mathrm{CH}_{2} \mathrm{CFCF}_{3}$-air flames is higher still. This is likely a result of a straight-chain reaction mechanism involving fluorine atoms (rather than the usual chain-branching radicals $\mathrm{H}, \mathrm{O}$, and $\mathrm{OH}$ ), which has a high temperature dependence. 


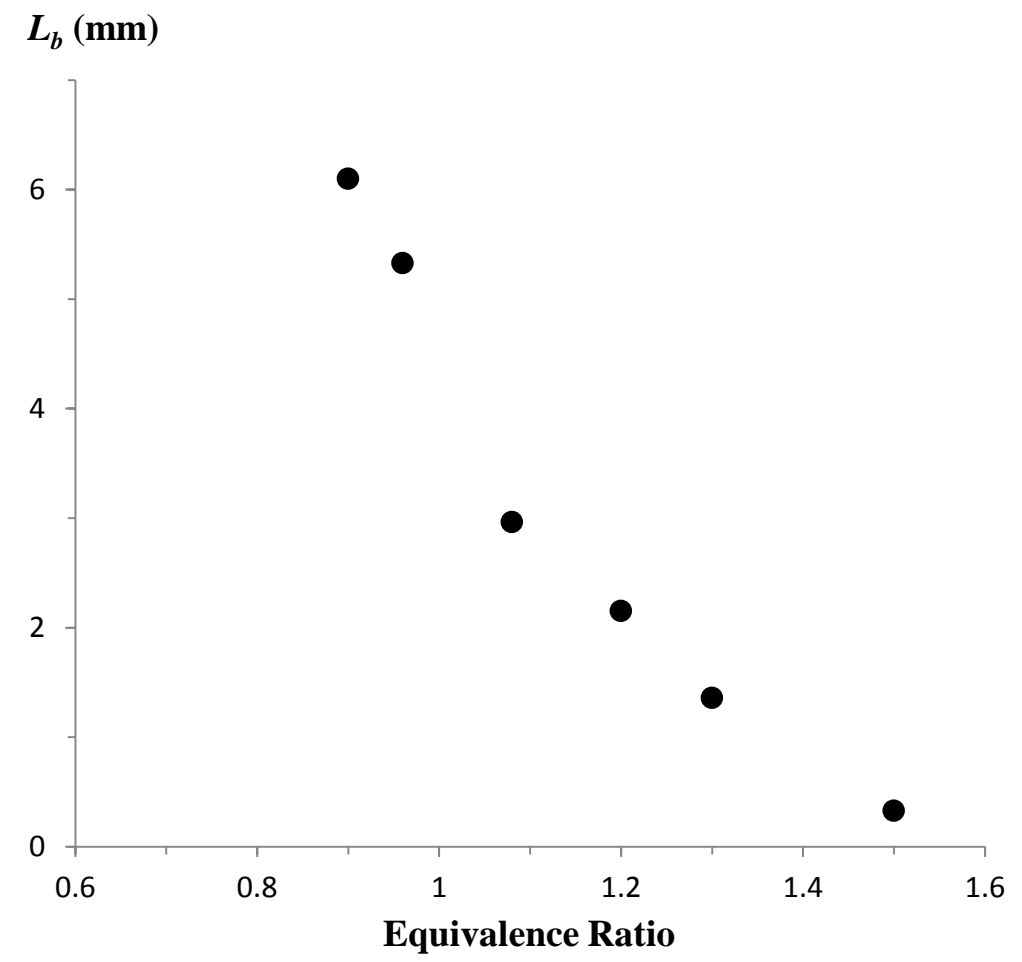

Fig. 10: Measured Markstein length for flames of $\mathrm{CH}_{2} \mathrm{~F}_{2}$ in air at various equivalence ratios.

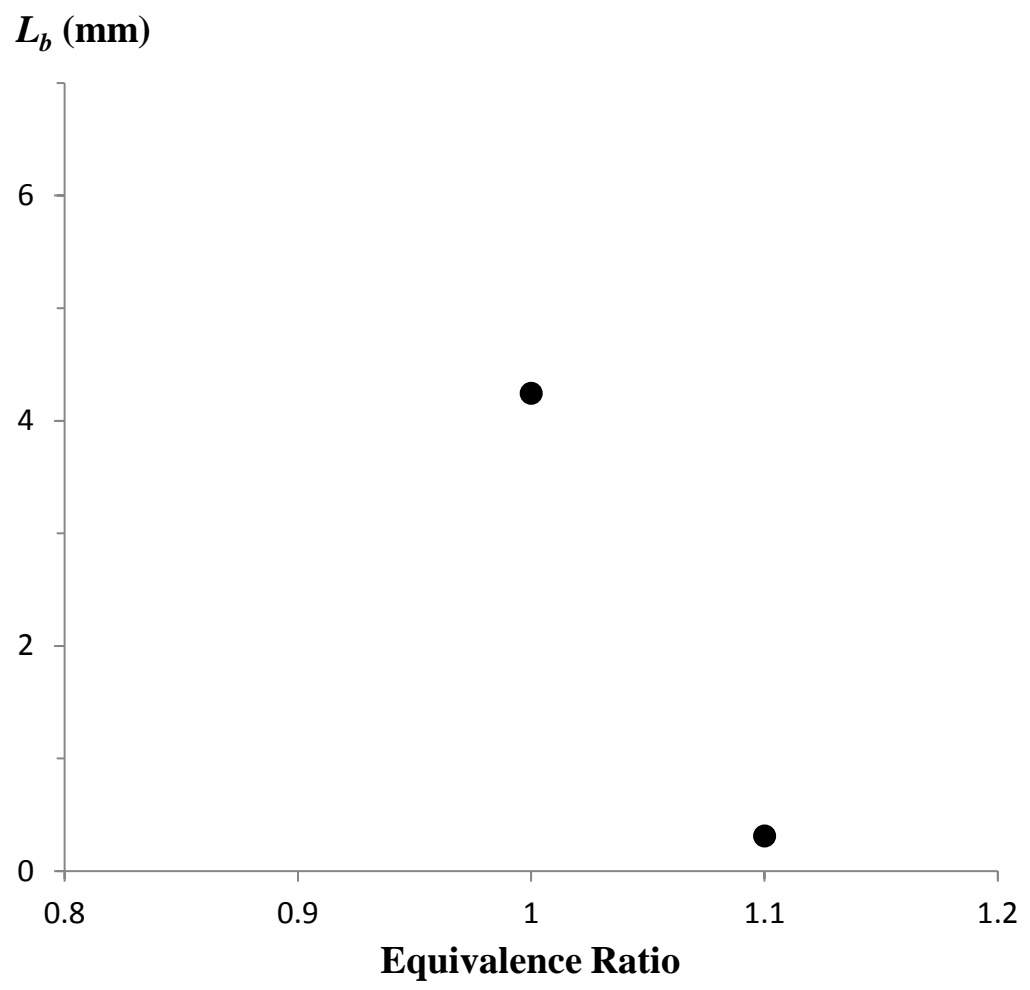

Fig. 11: Measured Markstein length for flames of $90 \% \mathrm{CH}_{2} \mathrm{~F}_{2} / 10 \% \mathrm{C}_{2} \mathrm{HF}_{5}$ (mass fraction) in air at various equivalence ratios. 
Lastly, the flame response to stretch, characterized by the Markstein length, can influence the turbulent burning velocity and thus influence the severity of ignition events at practical scales $[50,51]$. Previous studies have shown that the turbulent burning velocity can depend on the mixture Lewis number, even for mixtures with the same laminar un-stretched burning velocity that are subject to the same turbulence intensity. This was shown for typical hydrocarbon- or hydrogen-air mixtures, and the $\mathrm{CH}_{2} \mathrm{~F}_{2}$-air flames studied here have a much higher Markstein length and thus should have a larger response to flame stretch. Given the differing and high Markstein lengths of the refrigerant-air flames, consideration of the effects of stretch on the flame propagation may be important for understanding their full-scale flammability behavior.

\section{Conclusions}

The combustion behavior of two mildly flammable refrigerant-air mixtures has been studied. The burning velocity with respect to the product gases has been measured directly as a function of flame radius from shadowgraph images of the flame in an outwardly propagating flame configuration. Using a non-linear extrapolation to zero stretch, the un-stretched burning velocity with respect to the unburned gases $S_{u}{ }^{0}$ has been estimated. For mixtures of $\mathrm{CH}_{2} \mathrm{~F}_{2}$ in dry air, the burning velocity was measured for $0.90 \leq \phi \leq 1.5$. The present values of $S_{u}{ }^{0}$ are within the range of previous measurements (not stretch-corrected) for $\phi=0.9$ and $\phi=1.5$, and $10 \%$ to $20 \%$ higher than previous measurements for near-stoichiometric flames $(0.96 \leq \phi \leq 1.3)$. The present peak value of $S_{u}{ }^{0}$ was $7.5 \mathrm{~cm} / \mathrm{s}$ (at $\phi=0.96$ ) as compared to the previous values (not stretchcorrected) of $6.1 \mathrm{~cm} / \mathrm{s}$ to $6.7 \mathrm{~cm} / \mathrm{s}$ (at $\phi=1.03$ to $\phi=1.6$ ). The extrapolated values of $S_{u}{ }^{0}$ were $0 \%$ to $26 \%$ higher than the values of $S_{u}$ at the largest radii with experimental data, illustrating that the nature of the extrapolation is likely to have a significant effect of the extrapolated values of $S_{u}{ }^{0}$.

The value of $S_{u}{ }^{0}$ was also calculated numerically using the Sandia PREMIX code together with a kinetic model for hydrofluorocarbon combustion. The predicted burning velocities peaked at a value of $\phi$ very close to the experiments, with $S_{u}{ }^{0}=6.0 \mathrm{~cm} / \mathrm{s}$, which was about $20 \%$ lower than in the present experiment. The experiments showed a sharper reduction in $S_{u}{ }^{0}$ for leaner conditions than did the simulations. For mixtures of $\mathrm{CH}_{2} \mathrm{~F}_{2}$ and $\mathrm{C}_{2} \mathrm{HF}_{5}$ at mass fractions of 0.90 and 0.10 , respectively, the peak burning velocity was about $5.4 \mathrm{~cm} / \mathrm{s}$, which agreed very well with the numerical prediction.

The influence of stretch on the burning velocity was estimated. The measured Markstein lengths of the $\mathrm{CH}_{2} \mathrm{~F}_{2}$-air or $\mathrm{CH}_{2} \mathrm{~F}_{2} / \mathrm{CH}_{2} \mathrm{CFCF}_{3}$-air flames were a strong function of the equivalence ratio, increasing for leaner flames, and were higher than typically found for hydrocarbon-air or hydrogen-air flames. Hence, the burning velocities of the refrigerant-air flames were very sensitive to the stretch, and lean flames had a very large critical radii. The present results imply that stretch effects are very important for understanding the flammability behavior and flame propagation of refrigerant-air mixtures, and their consideration is important for their safe use.

In future work, improved methods of extrapolation to zero stretch, as well as data at larger flame radii, would improve the accuracy of the values of $S_{u}{ }^{0}$. Experiments at micro-gravity conditions would remove the effects of distortion due to buoyancy, which are possibly important 
in the present results, and will certainly be important for refrigerants with lower values of $S_{u}{ }^{0}$. Data for a wider range of refrigerants (and their mixtures) would be helpful to refine the experimental and analytic methods. Improvements in the kinetic models, and their extension to new refrigerants, would be very helpful for analysis of the underlying chemical processes. Finally, inclusion of radiative heat losses in the burning velocity calculations, as well as direct numerical simulation of spherically propagating flames would be valuable, so that the experimental data could be used directly to validate the kinetic model (eliminating the need for extrapolation to zero-stretch conditions).

\section{Acknowledgements}

This work was supported by Boeing and a NIST-ARRA grant to JLP. The authors would like to thank Dr. Kenji Takizawa and Prof. Li Qiao for input concerning the experimental setup.

\section{References}

[1] The Montreal Protocol on Substances that Deplete the Ozone Layer as Adjusted and/or Amended in London 1990, Copenhagen 1992, Vienna 1995, Montreal 1997, Beijing 1999, UNEP.

[2] G. J. Velders, A. R. Ravishankara, M. K. Miller, M. J. Molina, J. Alcamo, J. S. Daniel, D. W. Fahey, S. A. Montzka, S. Reimann, Preserving Montreal Protocol climate benefits by limiting HFCs, Science 335 (2012) 922-923.

[3] ASHRAE, ANSI/ASHRAE Standard 34-2010, Designation and Safety Classification of Refrigerants, ASHRAE, Atlanta, GA USA, 2010.

[4] ISO, ISO/DIS 817, Refrigerants-Designation and safety classification. Currently in final draft International Standard stage, International Organization for Standardization, Geneva, Switzerland, 2010.

[5] O. R. Hansen, P. Hinze, D. Engel, S. Davis, Using computational fluid dynamics (CFD) for blast wave predictions, Journal of Loss Prevention in the Process Industries 23 (2010) 885-906.

[6] H. Hisken, G. Enstad, P. Middha, K. van Wingerden, Investigation of concentration effects on the flame acceleration in vented channels, Journal of Loss Prevention in the Process Industries 36 (2015) 447-459.

[7] J. L. Pagliaro, N. Bouvet, G. T. Linteris, Premixed flame inhibition by $\mathrm{CF} 3 \mathrm{Br}$ and C3H2F3Br (2-BTP), Combust. Flame (submitted) (2015).

[8] L. K. Tseng, M. A. Ismail, G. M. Faeth, Laminar Burning Velocities and Markstein Numbers of Hydrocarbon/Air Flames, Combust. Flame 95 (1993) 410-426.

[9] S. Kwon, L. K. Tseng, G. M. Faeth, Laminar Burning Velocities and Transition to Unstable Flames in H2/O2/N2 and C3H8/O2/N2 Mixtures, Combust. Flame 90 (1992) 230-246.

[10] L. Qiao, C. Kim, G. Faeth, Suppression effects of diluents on laminar premixed hydrogen/oxygen/nitrogen flames, Combust. Flame 143 (2005) 79-96.

[11] M. I. Hassan, K. T. Aung, O. C. Kwon, G. M. Faeth, Properties of laminar premixed hydrocarbon/air flames at various pressures, Journal of Propulsion and Power 14 (1998) 479-488. 
[12] K. Takizawa, A. Takahashi, K. Tokuhashi, S. Kondo, A. Sekiya, Burning velocity measurement of fluorinated compounds by the spherical-vessel method, Combust. Flame 141 (2005) 298-307.

[13] U. J. Pfahl, M. C. Ross, J. E. Shephard, Flammability Limits, Ignition Energy, and Flame Speeds in H2-CH4-NH3-N2O-O2-N2 Mixtures, Combust. Flame 123 (2000) 140-158.

[14] L. Qiao, Y. Gan, T. Nishiie, W. J. A. Dahm, E. S. Oran, Extinction of premixed methane/air flames in microgravity by diluents: Effects of radiation and Lewis number, Combust. Flame 157 (2010) 1446-1455.

[15] Z. Chen, M. P. Burke, Y. Ju, Effects of compression and stretch on the determination of laminar flame speeds using propagating spherical flames, Combust. Theory and Modelling 13 (2009) 343-364.

[16] Z. Chen, On the accuracy of laminar flame speeds measured from outwardly propagating spherical flames: Methane/air at normal temperature and pressure, Combust. Flame 162 (2015) 2442-2453.

[17] D. Bradley, P. H. Gaskell, X. J. Gu, Burning velocities, Markstein lengths, and flame quenching for spherical methane-air flames: a computational study Combust. Flame 104 (1996) 176-198.

[18] F. Halter, T. Tahtouh, C. Mounaïm-Rousselle, Nonlinear effects of stretch on the flame front propagation, Combust. Flame 157 (2010) 1825-1832.

[19] Z. Chen, M. P. Burke, Y. Ju, Effects of Lewis number and ignition energy on the determination of laminar flame speed using propagating spherical flames, Proc. Combust. Inst. 32 (2009) 1253-1260.

[20] F. A. Williams, A review of some theoretical considerations of turbulent flame structure, in: AGARD Conference Proceeding, AGARD-CP-164, NATO Science and Technology Organization, 1975,

[21] P. D. Ronney, G. I. Sivashinsky, A Theoretical Study of Propagation and Extinction of Nonsteady Spherical Flame Fronts, J. Appl. Math. 49 (1989) 1029-1046.

[22] A. P. Kelley, J. K. Bechtold, C. K. Law, Premixed flame propagation in a confining vessel with weak pressure rise, Journal of Fluid Mechanics 691 (2011) 26-51.

[23] A. E. Lutz, F. M. Rupley, R. J. Kee, W. C. Reynolds, E. Meeks, EQUIL: A CHEMKIN implementation of STANJAN for computing chemical equilibria, S. N. Laboratories, Reaction Design, Inc., 6500 Dublin Boulevard, Dublin, CA 94568. Software and manual authorized by Ellen Meeks and Fran Rupley, 1998.

[24] M. I. Hassan, K. T. Aung, G. M. Faeth, Measured and predicted properties of laminar premixed methane/air flames at various pressures, Combust. Flame 115 (1998) 539-550.

[25] G. Rozenchan, D. L. Zhu, C. K. Law, S. D. Tse, Outward propagation, burning velocities, and chemical effects of methane flames up to 60 atm, Proc. Combust. Inst. 20 (2002) 1461-1469.

[26] X. J. Gu, M. Z. Haq, M. Lawes, R. Woolley, Laminar Burning Velocity and Markstein Lengths of Methane-Air Mixtures, Combust. Flame 121 (2000) 41-58.

[27] C. M. Vagelopoulos, F. N. Egolfopoulos, Direct Experimental Determination of Laminar Flame Speeds, Proc. Combust. Inst. 27 (1998) 513-519.

[28] O. Park, P. S. Veloo, N. Liu, F. N. Egolfopoulos, Combustion characteristics of alternative gaseous fuels, Proc. Combust. Inst. 33 (2011) 887-894. 
[29] G. Jomaas, X. L. Zheng, D. L. Zhu, C. K. Law, Experimental determination of counterflow ignition temperatures and laminar flame speeds of C2-C3 hydrocarbons at atmospheric and elevated pressures, Proc. Combust. Inst. 30 (2005) 193-200.

[30] R. J. Kee, J. F. Grcar, M. D. Smooke, J. A. Miller, A fortran computer program for modeling steady laminar one-dimensional premixed flames, Report No. SAND85-8240, Sandia National Laboratories, Livermore, CA, USA, 1991.

[31] R. J. Kee, G. Dixon-Lewis, J. Warnatz, R. E. Coltrin, J. A. Miller, A fortran computer package for the evaluation of gas-phase, multicomponent transport properties, Report No. SAND86-8246, Sandia National Laboratories, Livermore, CA, USA, 1986.

[32] R. J. Kee, F. M. Rupley, J. A. Miller, CHEMKIN-II: A fortran chemical kinetics package for the analysis of gas phase chemical kinetics, Report No. SAND89-8009B, Sandia National Laboratories, Livermore, CA, USA, 1989.

[33] D. R. Burgess, M. R. Zachariah, W. Tsang, P. R. Westmoreland, Thermochemical and chemical kinetic data for fluorinated hydrocarbons, Prog. Energy Combust. Sci. 21 (1995) 453-529.

[34] D. Burgess, M. R. Zachariah, W. Tsang, P. R. Westmoreland, Thermochemical and Chemical Kinetic Data for Fluorinated Hydrocarbons, Report No. NIST Technical Note 1412, Gaithersburg, MD, 1995.

[35] V. I. Babushok, G. T. Linteris, O. Meier, Combustion properties of halogenated fire suppressants, Combust Flame 159 (2012) 3569-3575.

[36] J. L. Pagliaro, G. T. Linteris, V. I. Babushok, Premixed flame inhibition C2HF3Cl2 and C2HF5, Combust. Flame 163 (2015) 54-65.

[37] K. Takizawa, K. Tokuhashi, S. Kondo, Flammability assessment of CH2=CFCF3: Comparison with fluoroalkenes and fluoroalkanes, Journal of Hazardous Materials 172 (2009) 1329-1338.

[38] C. K. Law, Dynamics of Stretched Flames, Twenty-Second Symposium on Combustion (1988) 1381-1402.

[39] P. Clavin, Dynamic Behavior of Premixed Flame Fronts in Laminar and Turbulent Flows, Prog. in Energy and Combust. Sci. 11 (1985) 1-59.

[40] M. Matalon, On flame stretch, Combust. Sci. Technol. 31 (1983) 169-181.

[41] A. P. Kelley, G. Jomaas, C. K. Law, Critical radius for sustained propagation of sparkignited spherical flames, Combust. Flame 156 (2009) 1006-1013.

[42] Z. Chen, M. P. Burke, Y. Ju, On the critical flame radius and minimum ignition energy for spherical flame initiation, Proc. Combust. Inst. 33 (2011) 1219-1226.

[43] K. Takizawa, A. Takahashi, K. Tokuhashi, S. Kondo, A. Sekiya, Burning velocity measurement of fluorinated compounds by the spherical-vessel method, Combust. Flame 141 (2005) 298-307.

[44] K. Takizawa, N. Igarashi, K. Tokuhashi, S. Kondo, M. Mamiya, H. Nagai, Assessment of Burning Velocity Test Methods for Mildly Flammable Refrigerants, Part 2: VerticalTube Method, ASHRAE Trans. 119 (2013) 255-264.

[45] K. Takizawa, S. Takagi, K. Tokuhashi, S. Kondo, M. Mamiya, H. Nagai, Assessment of Burning Velocity Test Methods for Mildly Flammable Refrigerants, Part 1: ClosedVessel Method, ASHRAE Trans. 119 (2013) 243-254.

[46] T. Jabbour, Flammable Refrigerant Classification Based on the Burning Velocity, Ph.D. Thesis, Ecole des Mines de Paris, Paris France, 2004. 
[47] D. Clodic, T. Jabbour, Method of test for burning velocity measurement of flammable gases and results, HVAC\&R Research 17 (2011) 51-75.

[48] T. Jabbour, D. F. Clodic, Burning Velocity and Refrigerant Flammability Classification, ASHRAE Trans. 110 (2004) 522-533.

[49] R. A. Strehlow, d. L. Reuss, Effect of a zero g environment on flammability limits as determined using a standard flammability tube apparatus, Report No. NASA-CR-3259, National Aeronautic and Space Administration, Washington, DC, 1980.

[50] J. B. Bell, R. K. Cheng, M. S. Day, I. G. Shepherd, Numerical simulation of Lewis number effects on lean premixed turbulent flames, Proc. Combust. Inst. 31 (2007) 13091317.

[51] F. Dinkelacker, B. Manickam, S. Muppala, Modelling and simulation of lean premixed turbulent methane/hydrogen/air flames with an effective Lewis number approach, Combust. Flame 158 (2011) 1742-1749. 